\title{
Correction to: The effectiveness of ultrasound examination to assess the healing process of bone lesions of the jaws: a systematic review
}

\author{
Davide Musu $^{1}$ (D) Hagay Shemesh ${ }^{2} \cdot$ Michela Boccuzzi $^{1} \cdot$ Claudia Dettori $^{1} \cdot$ Elisabetta Cotti $^{1}$
}

Published online: 12 October 2020

(C) Springer-Verlag GmbH Germany, part of Springer Nature 2020

\section{Correction to: Clinical Oral Investigations} https://doi.org/10.1007/s00784-020-03339-9

The given names of the authors are swapped with their family names. The correct names to be cited should be changed from: Musu Davide ${ }^{1}$, Shemesh Hagay ${ }^{2}$, Boccuzzi Michela ${ }^{3}$, Dettori Claudia ${ }^{3}$, Cotti Elisabetta ${ }^{1}$ to Davide Musu ${ }^{1}$. Hagay Shemesh ${ }^{2} \cdot$ Michela Boccuzzi $^{1} \cdot$ Claudia Dettori ${ }^{1}$. Elisabetta Cotti ${ }^{1}$.

Publisher's Note Springer Nature remains neutral with regard to jurisdictional claims in published maps and institutional affiliations.

The original article can be found online at https://oi.org/10.1007/ s00784-020-03339-9

Davide Musu

davidemusu.dds@gmail.com

1 Department of Conservative Dentistry and Endodontics, University of Cagliari, Cagliari, Sardegna, Italy

2 Department of Endodontology, Academic Centre for Dentistry Amsterdam (ACTA), Amsterdam, Netherlands 